cytomegalovirus infection and found it to be a cost-effective new treatment for cytomegalovirus infection that deserves further study.

Disclosure of Interest: None declared

DOI: 10.1136/annrheumdis-2017-eular.2128

\section{SAT0579 LOW DOSE IL-2 RESTORES IMBALANCE BETWEEN TH17 AND REGULATORY T CELLS IN PATIENTS WITH CONNECTIVE DISEASE COMBINED EBV/CMV VIREMIA}

Q. Wang, C. Wang. Rheumatology, The second hospital of Shanxi medical university, TaiYuan, China

Background: DMARDs are the most important medicine in treatment of autoimmune disease. However, excessive using DMARDs lead to decrease immune-function, which increasing opportunistic infection, such as EBV, CMV viremia. Recent study show the imbalance between T help cell 17 (Th17) and regulatory $T$ cell (Treg cell) is a pivotal cause of autoimmune disease and correction of this imbalance to be a potential therapy. So whether low dose IL-2 restores the balance of Th17/Treg and improve immune function?

Objectives: To investigate the effect of low-dose IL-2 on Treg and effector lymphocyte subsets in patients with connective tissue disease (CTD) combined EBV or CMV viremia.

Methods: Clinical records of 70 CTD patients combined EBV or CMV viremia, hospitalized from May 2012 to January 2017 in the second Hospital of ShanXi medical university (Group infection), were analyzed. The group includes 21 patients who received rhlL-2 after infected CMV or EBV, and 12 continue receiving DMARDs. As control, we selected 70 health persons (Group health) whose age matched with group infection, 70 naïve CTD patients with no treatment (Group treatment-naïve), and 70 CTD without viremia patients having glucocorticoid and DMARDS medical history (Group Treatment-DMARDS). The two groups' underlying diseases are matched with the Group infection. The absolute numbers and proportions of peripheral lymphocytes (T cells, B cells, NK cells, the total number of the three cells, CD4+ T cells, CD8+ T cells), and CD4+ T cell subsets (Th1, Th2, Th17, Treg cells and Th1/Th2, Th17/Treg) were examined by flow cytometry.

Results: 1. The absolute count of Treg cells in the Group treatment-naïve was significantly low and Th17/Treg was notable increase compared with the Group health $(\mathrm{P}<0.05)$. The peripheral lymphocytes and Treg cells are notable low $(P<0.05)$ and Th17/Treg was significantly increase $(P<0.05)$ in the Group treatment-DMARDs compared with the Group treatment-naïve.

2. The peripheral lymphocytes, CD4+T cells subsets except Treg cells and Th1/Th2, Th17/Treg are significantly decrease in the Group infection compared with the Group treatment-DMARDs $(P<0.05)$. While the absolute count of Treg cell was no different between the two groups.

3. After the course of rhlL-2 treatment, there were significantly increase of the peripheral lymphocytes and CD4+T cells subsets $(P<0.01)$. Th17/Treg was significantly low after treatment. Compared with the patients who continue receiving DMARDs, all lymphocytes subsets had a rising trend in patients receiving rhIL-2 treatment.

Conclusions: The decrease of Treg cell number and imbalance of Th17/Treg may contribute to the pathogenesis of CTD. Excessive using glucocorticoid and DMARDs may augment this imbalance. On the other hand, these medicines decrease immune function, which leads to EBV and CMV viremia. Over the treatment of rhlL-2, immune function was improved and there was a more significant increase in the absolute count of Treg cells than Th17, and a consequently restore the balance of Th17/Treg.

\section{References:}

[1] Miyara M, Ito $Y$, Sakaguchi S. TREG-cell therapies for autoimmune rheumatic diseases. Nature reviews Rheumatology 2014;10:543-51.

[2] Klatzmann D, Abbas AK. The promise of low-dose interleukin-2 therapy for autoimmune and inflammatory diseases. Nature reviews Immunology 2015;15:283-94.

Disclosure of Interest: None declared

DOI: 10.1136/annrheumdis-2017-eular.6247

\section{SAT0580 OSTEOARTICULAR TUBERCULOSIS: A RETROSPECTIVE STUDY OF 119 CASES}

R. Sonia, S. Boussaid, I. Abdelkafi, S. Hela, C. Ilhem, E. Mohamed. Rheumatology, la Rabta, Tunis, Tunisia

Background: Bone and joint involvement in tuberculosis is uncommon. Wile osteoarticular tuberculosis most commonly occurs in the vertebral column, less frequently affected sites are the hip, knee and sacroiliac joints. The multifocal form of skeletal tuberculosis is exceptional.

Objectives: To evaluate the clinical and diagnostic features of osteoarticular tuberculosis.

Methods: We reviewed the files of all patients admitted to our department from 2000 to 2015 with a diagnosis of osteoarticular tuberculosis.

Results: We identified 119 patients (52 men, 67 female), having osteoarticular tuberculosis lesions. Mean age was 43 years [21-82]. Diagnosis delay was 4 months. Pain, low-grade fever and loss of weight were the most common presenting symptoms. All the patients consulted because of pain. The spine was involved in 81 patients. Peripheral osteoarticular tuberculosis was diagnostic in 38 cases, mainly in the knee ( 21 cases). Five patients have a multifocal involvement of the osteoarticular tuberculosis. The tuberculin skin test was positive in $75 \%$ of the cases. The diagnosis of spondylodiscitis was provided by CT-scan and /or magnetic resonance imaging. Paraspinal and epidural abscesses has been reported in 11 cases. Bacteriological and /or pathological diagnosis was made in 72 cases $(60.5 \%)$. The Quantiferon test was done in 7 cases and was positive. The antibiotic treatment led to recovery in all cases. Tree patients have presented neurological signs.

Conclusions: Our results were similar to those of the literature. Elderly population was especially at risk. The idiagnosis can be delayed espacially in negative investigations. Therefore it is recommendable to do a very large screening tests especially in endemic areas.

Disclosure of Interest: None declared

DOI: 10.1136/annrheumdis-2017-eular.6911

\section{SAT0581 NON-TUBERCULOUS MYCOBACTERIAL (NTM) INFECTION IN PATIENTS WITH RHEUMATIC DISEASES: POSSIBLE IMPORTANCE OF PULMONARY BARRIER FUNCTION RATHER THAN SYSTEMIC IMMUNE STATE IN THE DEVELOPMENT AND EXACERBATION OF NTM INFECTION}

S. Takenaka ${ }^{1}$, H. Kameda ${ }^{1}$, T. Ogura ${ }^{1}$, H. Oshima ${ }^{2}$, K. Izumi ${ }^{3}$, A. Hirata ${ }^{1}$, H. Ito ${ }^{1}$, Y. Fujisawa ${ }^{1}$ on behalf of Department of Connective Tissue Diseases, National Tokyo Medical Center. ${ }^{1}$ Rheumatorogy, Toho University Ohashi Medical Center; ${ }^{2}$ Rheumatorogy, Department of Connective Tissue Diseases, National Tokyo Medical Center; ${ }^{3}$ Rheumatorogy, Division of Rheumatology, Department of Internal Medicine, Keio University School of Medicine, Tokyo, Japan

Objectives: To identify the risk factors of the development and exacerbation of NTM infection in patients with rheumatic diseases.

Methods: Among 7013 patients with rheumatic diseases visiting Toho University Ohashi Medical Center and Tokyo Medical Center, 20 patients were enrolled in this study by fulfilling the diagnostic criteria of NTM infection by The Japanese Society for Tuberculosis and The Japanese Respiratory Society, and being followed-up for more than 1 year. The medical records of enrolled patients were retrospectively reviewed.

Results: Eleven patients with rheumatoid arthritis, 4 patients with vasculitis, 3 patients with Sjögren's syndrome and 1 patient with dermatomyositis and systemic lupus erythematosus for each were enrolled in this study. Mycobacterium avium complex (MAC) was detected in 13 patients, $M$. chelonae in 2 patients, $M$. abscessus and M.kansasii in 1 patient each, and undetermined mycobacterium in 3 patients. Notably, bronchiectasis was the predominant pulmonary complication observed in 13 patients, and interstitial lung disease was observed in 5 patients. Although 7 patients experienced the exacerbation of NTM during the observation period, immunological state on NTM diagnosis including peripheral blood leukocyte (median $5.8 \times 10^{3}$ versus $7.0 \times 10^{3} / \mu \mathrm{L} ; \mathrm{p}=0.72$ ), lymphocyte (median $1.3 \times 10^{3}$ versus $1.1 \times 10^{3} / \mu \mathrm{L} ; \mathrm{p}=0.10$ ) and the serum IgG level (median 1379 $\mathrm{mg} / \mathrm{dL}$ versus $1207 \mathrm{mg} / \mathrm{dL} ; \mathrm{p}=0.20$ ) were within normal ranges and comparable between ever and never exacerbated patients, respectively, as well as the treatments for rheumatic diseases such as glucocorticoids and biological agents. Conclusions: NTM infection in patients with rheumatic diseases develops based on the dysfunction of pulmonary barrier rather than the systemic immunosuppression.

Disclosure of Interest: None declared

DOI: 10.1136/annrheumdis-2017-eular.3357

\section{SAT0582 CHAGAS' DISEASE IN PATIENTS WITH AUTOIMMUNE DISEASES RECEIVING IMMUNOSUPPRESSIVE THERAPY. ANALYSIS OF 48 CASES}

$\underline{\text { S. Retamozo }}^{1,2}$, M.J. Haye Salinas ${ }^{2}$, A. Alvarellos ${ }^{2}$, V. Saurit ${ }^{2}$, F. Caeiro ${ }^{2}$, J.P. Caeiro $^{3}$, V. Carballo ${ }^{4}$, M. Medeot ${ }^{4}$, O. Salomone ${ }^{5}$, R. Albertini ${ }^{6}$, F. Merschon ${ }^{7}$, F. Bonisconti ${ }^{8}$, A. Sanchez ${ }^{8}$, T. Alvarellos ${ }^{8} .{ }^{1}$ INICSA, CONICET; ${ }^{2}$ Rheumatology; ${ }^{3}$ Infectious Diseases, Hospital Privado Universitario de Córdoba; ${ }^{4}$ Infectious Diseases, Hospital Raúl A Ferreyra; ${ }^{5}$ Cardiology, Hospital Privado Universitario de Córdoba; ${ }^{6}$ Internal Medicine, Hospital Privado Universitario; ${ }^{7}$ Cátedra de Física Biomédica, Secretaria de Ciencia y Tecnología (SECYT), Universidad Nacional de Córdoba; ${ }^{8}$ Molecular Biology, Hospital Privado Universitario de Córdoba, Cordoba, Argentina

Objectives: To analyze the main features at diagnosis and Chagas' Disease (CD) reactivation in patients with autoimmune diseases $(A D)$ receiving immunosuppressive therapy (IT).

Methods: 13 patients with AD diagnosed with $C D$ admitted to our Units between January to December 2016. In addition, we performed a systematic analysis of cases reported to date through a MEDLINE search. Inclusion criteria 1) adults with $\mathrm{AD}$ treat with $\mathrm{iT}$ (glucocorticoids [GC], disease-modifying anti rheumatic drugs [DMARDs] and biological drugs [BD]); 2) had confirmed or were positive for 2 serological test for CD. Reviews, experimental studies, duplicate publications, and abstracts were excluded.

Results: A total of 48 patients (13 from our Units and 35 from the literature search) fulfilled the inclusion criteria. There were $41(85.4 \%)$ women, mean age of 